\title{
Emergence of New Injectable Lipid Emulsions in the USA: Guidance for Pediatric Clinicians
}

\author{
Oscar R. Herrera ${ }^{1,2^{*}}$, Lisa A. Caviness ${ }^{1}$, Richard A. Helms ${ }^{1,2,3}$ \\ ${ }^{1}$ Department of Clinical Pharmacy and Translational Science, University of Tennessee Health Science Center, Memphis, TN, USA \\ ${ }^{2}$ State of Tennessee Center for Pediatric Experimental Therapeutics, Memphis, TN, USA \\ ${ }^{3}$ Department of Pediatrics, University of Tennessee Health Science Center, Memphis, TN, USA \\ Email: *oherrera@uthsc.edu
}

How to cite this paper: Herrera, O.R., Caviness, L.A. and Helms, R.A. (2019) Emergence of New Injectable Lipid Emulsions in the USA: Guidance for Pediatric Clinicians. Food and Nutrition Sciences, 10, 823-833.

https://doi.org/10.4236/fns.2019.107060

Received: June 18, 2019

Accepted: July 27, 2019

Published: July 30, 2019

Copyright (C) 2019 by author(s) and Scientific Research Publishing Inc. This work is licensed under the Creative Commons Attribution International License (CC BY 4.0).

http://creativecommons.org/licenses/by/4.0/

\begin{abstract}
With the advent of new, particularly mixed-oil lipid emulsions approved by the United States Food \& Drug Administration (FDA), clinicians have more options when choosing one as part of the parenteral nutrition support of patients. Lipid products long-standing availability in Europe and other parts of the world has certainly facilitated the process in the United States, where there was little evolution before 2014. These newer oil-based emulsions are finding their way to be used in pediatrics, as studies are being carried out that will result in pediatric labeling. Pediatric clinicians may find themselves wondering how these lipid emulsions are different from those that have come before; whether the same dosing or administration practices apply as with the traditional soybean-oil lipid emulsion, and if they can be used for other more emergent interventions. We present this review of the current lipid emulsions available in the U.S. market, highlighting the differences among them, as well as, providing some practical information for clinicians that can assist them in their day-to-day duties.
\end{abstract}

\section{Keywords}

Lipid Emulsions, Fatty Acids, Parenteral Nutrition, Pediatrics

\section{Introduction}

Parenteral nutrition (PN) as a medical intervention has been a part of clinical practice since the 1970s. Generally, PN solutions consist of protein, dextrose, lipids, water, electrolytes, vitamins, trace elements, and other nutritional components that are tailored to a patient's individual needs. Indications for pediatric PN range from congenital gut malformations, perinatal intestinal disease, 
malnutrition, critical care, perioperative support, and growth/development aid in pediatrics [1]. Injectable lipid emulsions (ILEs) are advantageous to clinicians, providing caloric density, and essential fatty acids in an iso-osmolar dosage form. It is also worth noting that ILEs can also be utilized off label as a treatment for certain types of toxic ingestions/poisonings; they are thought to act as a "lipid sink" [2]. In the US, plant-based emulsions derived from soybean oil have historically been the emulsion of choice. However, more recent studies have indicated that emulsions with a combination of soy, olive, and fish oils in addition to medium-chain triglycerides (MCTs) may be more beneficial through down-regulation of inflammation, immunomodulation, and potentially improving clinical outcomes [3]. Our review aims to explore the 3 newer lipid emulsions approved for use in the United States in the past 7 years: Clinolipid $^{\circledR}$ (Baxter, Deerfield, IL), Smoflipid ${ }^{\circledR}$ (Fresenius Kabi, Uppsala, Sweden) and Omegaven ${ }^{\circledR}$ (Fresenius Kabi) plus the long-standing lipid emulsions, Intralipid $^{\circledR}$ (Fresenius Kabi,) and Nutrilipid ${ }^{\circledR}$ (BBraun Medical Inc., Bethelhem, PA) to give a historical context. Specifically, each emulsion will be evaluated on its effect on circulating fatty acids and plasma triglycerides, safety monitoring and contribution to weight gain or maintenance, where available. Notable studies indicating harm or benefit shall also be included in the analyses of these ILEs. For general information related to the administration, dosing, storage, preparation, and general risks, such as infection associated with the administration of IV preparations, package inserts and clinical practice guidelines should be referenced. Refer to Table 1 for a general summary of the content of these lipid emulsions.

\section{Soybean-Oil Lipid Emulsions}

Intralipid $^{\circledR}$ and Nutrilipid ${ }^{\circledR}$ are soybean oil-based ILEs. They consist of approximately $50 \%$ omega- 6 fatty acids (linoleic acid), $25 \%$ of omega- 9 (oleic acid) and $\sim 10 \%$ of omega- 3 fatty acids ( $\alpha$-linolenic acid). Both have FDA approval for use in adults and pediatrics, and carry the risk of fat overload syndrome (package inserts). Other notable complications include hypercholesterolemia, hypertriglyceridemia, and metabolic stress which may be associated with endothelial stress [4] [5]. In a comparative study that evaluated the uptake and incorporation of fatty acids into cells, soybean oil- and olive oil- based ILEs were found to improve cell viability, while fish-oil based ILEs were found to negatively impact cell viability [6]. It is noteworthy that this study also demonstrated that soybean oil-based emulsions have a higher induction of NF- $\kappa \mathrm{B}$ compared to fish-oil based emulsions, which may correlate with some of the liver complications observed with long-term use of the former [6]. There also may be implications in the preferential use of ILEs with MCTs as a lipid sink for local anesthetic poisoning compared to soybean-only ILEs [2].

Studies have demonstrated that Intralipid ${ }^{\circledR}$ is an effective emulsion to use for the prevention of essential fatty-acid deficiency (EFAD) and for weight gain in 
Table 1. FDA approved injectable lipid emulsions (ILEs).

\begin{tabular}{|c|c|c|c|c|c|}
\hline & $\begin{array}{c}\text { Intralipid }^{\circledR} \\
\text { (Fresenius Kabi) } \dagger^{\text {(Fen }}\end{array}$ & Nutrilipid $^{\circledR}$ (BBraun) $\ddagger$ & Clinolipid $^{\circledR}(\text { Baxter })^{\mathrm{r}}$ & $\begin{array}{c}\text { Smoflipid }^{\circledR} \\
(\text { Fresenius Kabi)^ }\end{array}$ & $\begin{array}{c}\text { Omegaven }^{\circledR} \\
\text { (Fresenius Kabi)\| }\end{array}$ \\
\hline Oil Source & Soybean & Soybean & Soybean/Olive Oil & $\begin{array}{l}\text { Soybean/MCT/ } \\
\text { Olive/Fish }\end{array}$ & Fish Oil \\
\hline \multicolumn{6}{|l|}{ Fatty acid content } \\
\hline Linoleic & $44 \%-62 \%$ & $48 \%-58 \%$ & $13.8 \%-22 \%$ & $14 \%-25 \%$ & $1.5 \%$ \\
\hline Oleic & $19 \%-30 \%$ & $17 \%-30 \%$ & $44.3 \%-79.5 \%$ & $23 \%-35 \%$ & $4 \%-11 \%$ \\
\hline Palmitic & $7 \%-14 \%$ & $9 \%-13 \%$ & $7.6 \%-19.3 \%$ & $7 \%-12 \%$ & $4 \%-12 \%$ \\
\hline$\alpha$-Linolenic & $4 \%-11 \%$ & $4 \%-11 \%$ & $0.5 \%-4.2 \%$ & $1.5 \%-3.5 \%$ & $1.1 \%$ \\
\hline Palmitoleic & -- & -- & $0 \%-3.2 \%$ & -- & $4 \%-10 \%$ \\
\hline Caprylic & -- & -- & -- & $14 \%-25 \%$ & -- \\
\hline Capric & -- & -- & -- & $5 \%-15 \%$ & -- \\
\hline Stearic & $1.4 \%-5.5 \%$ & $2.5 \%-5 \%$ & $0.7 \%-5 \%$ & $1.5 \%-4 \%$ & -- \\
\hline Arachidonic & -- & -- & -- & -- & $0.2 \%-2 \%$ \\
\hline Myristic & -- & -- & -- & -- & $2 \%-7 \%$ \\
\hline Eicosapentanoic & -- & -- & -- & $1 \%-3.5 \%$ & $13 \%-26 \%$ \\
\hline Docosahexanoic & -- & -- & -- & $1 \%-3.5 \%$ & $14 \%-27 \%$ \\
\hline $\begin{array}{l}\text { Phosphorus } \\
\text { (per } 100 \mathrm{~mL} \text { ) }\end{array}$ & $1.5 \mathrm{mmol}$ & N/A & $1.5 \mathrm{mmol}$ & $1.5 \mathrm{mmol}$ & $1.5 \mathrm{mmol}$ \\
\hline Egg phospholipid, \% & 1.2 & 1.2 & 1.2 & 1.2 & 1.2 \\
\hline Osmolarity (mOsm/L) & 260 & 290 & 260 & 270 & 273 \\
\hline Supplied as & $\begin{array}{l}100 / 250 / 500 / \\
1000 \mathrm{~mL} \text { bags }\end{array}$ & $\begin{array}{c}250 / 350 \mathrm{~mL} \text { in } 500 \mathrm{~mL} \\
\text { containers; } 500 / 1000 \mathrm{~mL} \text { bags }\end{array}$ & $1000 \mathrm{~mL}$ & $100 / 250 / 500 \mathrm{~mL}$ bags & $50 / 100 \mathrm{~mL}$ glass bottles \\
\hline
\end{tabular}

MCT: medium-chain triglycerides; N/A: not available. $\dagger\left[\right.$ Intralipid $\left.^{\mathbb{}}\right]$ package insert. $\ddagger\left[\right.$ Nutrilipid $\left.^{\circledR}\right]$ package insert. $y\left[\right.$ Clinolipid $\left.^{\circledR}\right]$ package insert. $\wedge\left[\right.$ Smoflipid $\left.{ }^{\circledR}\right]$ package insert. $\|\left[\right.$ Omegaven $\left.^{\circledR}\right]$ package insert.

infants [7]. There may be potential for other ILEs to adequately prevent the development of EFAD when a patient is provided with at least $3.2 \%$ of total calories given as fat via the intravenous route [8]. Generally, $3 \%-4 \%$ of total calories has been found to be sufficient in the prevention of the development of EFAD, though this range may differ for different patient groups. Furthermore, Intralipid $^{\circledR}$ has been demonstrated as tolerable in aggressive nutrition therapy for very low birth weight (VLBW) infants [9]. In terms of antioxidant properties, there seems to be no significant difference with other ILEs [10]. Soybean-oil based ILEs have been shown to produce blood pressure elevations. Siqueira and colleagues demonstrated reduced endothelial-dependent brachial artery dilatation in healthy volunteers after infusion of a soybean-oil-based ILE as opposed to those who received an olive-oil based ILE or a lipid-free PN solution. The mechanism remains unexplained since there were no changes in plasma free fatty-acid concentrations in all subjects receiving ILE [11]. Overproduction of free fatty acids has been linked to endothelial dysfunction. 
Hypertriglyceridemia associated with the use of soybean lipid emulsions can be attenuated with the brief discontinuation of the solution [12]. Adverse effects, such as pancreatitis and hypertriglyceridemia are more highly associated with $10 \%$ formulations than $20 \%$ formulations due to interference with enzymes that metabolize fatty acids [13]. A study demonstrated that when administering 0.5 $\mathrm{g} / \mathrm{kg} /$ day lipid or 0.5 increased to $2.0 \mathrm{~g} / \mathrm{kg} / \mathrm{d}$ over 5 days that the group with the increasing treatment triene: tetraene ratios decreased, linoleate levels increased when compared to the group that remained at $0.5 \mathrm{~g} / \mathrm{kg} / \mathrm{day}$. This study also concluded that infants receiving $1 \mathrm{~g} / \mathrm{kg} /$ day exhibited a higher risk of hypertriglyceridemia than those receiving $0.5 \mathrm{~g} / \mathrm{kg} / \mathrm{day}$, which had no infants develop hypertriglyceridemia [14]. Soybean oil-based ILEs certainly carry most of the available literature regarding $Y$-site compatibility with other medications. They have been, by far, the most studied for other purposes besides nutrition support and perhaps the reason why their place in medical care remains across hospitals and infusion centers.

\section{Fish-Oil Lipid Emulsion}

Omegaven ${ }^{\circledR}$ is the most recent lipid emulsion approved in the United States and already with approval in pediatrics. Same precautions apply as with all ILEs in regards to fat overload syndrome and risk of hypertriglyceridemia. Significant differences that clinicians should be aware of note, it is a different concentration, just $10 \%$. Per labeling, it can only be administered by itself over 12 hours or as part of 3-in-1 admixture over 24 hours, and at a maximum dose of $1 \mathrm{~g} / \mathrm{kg} / \mathrm{day}$. Pediatric practitioners have longed for its approval since it is a pure fish-oil based ILE, suggesting immunomodulatory and anti-inflammatory benefits. Many studies have postulated that consistent, high intake of omega- 6 fatty acids in soybean oil ILEs leads to accumulation of lipophilic bile acids. This, in turn, can activate cell receptors leading to hepatocyte apoptosis. Omega-3 fatty acids instead have been shown to attenuate this programmed cell death [15]. Previous evidence demonstrated positive outcomes for patients when administered via the enteral route [16]. Omegaven ${ }^{\circledR}$ has been shown to halt the progression of parenteral nutrition-associated liver disease (PNALD), and even reverse the biochemical manifestations of this condition after replacement with such emulsions [17] [18] [19]. As shown in Table 1, Omegaven ${ }^{\circledR}$ has negligible amounts of essential fatty-acids, linoleic and $\alpha$-linolenic acid, raising concerns about the development of EFAD in patients receiving this emulsion long-term. So far, clinical evidence is showing tolerability. A study on 21 patients at Boston Children's hospital revealed only a single case of EFAD, defined by a triene: tetraene ratio $>0.2$ attributed to ILE discontinuation; as well as no significant differences in other safety measures when compared to historical controls receiving soybean-oil based emulsions [20]. Investigators argue that since the end products needed are being provided in arachidonic acid, eicosapentanoic acid (EPA) and docosahexanoic acid (DHA), that perhaps concerns for EFAD are not increased [21]. With more 
widespread use in North America, more studies should be published analyzing its long-term effects. The rest of the world led by Europe may be a step ahead since usage has shifted from these single-source ILEs to mixed-oil ones. These newer generation ILEs will be described in the following section.

\section{Mixed-Oil Lipid Emulsions}

\subsection{Clinolipid}

Clinolipid ${ }^{\circledR}$ is a mixture of olive oil (80\%) and soybean oil (20\%) (package insert). Similarly to soybean-based emulsions, it was shown to benefit cell viability but also lead to higher induction of NF- $\kappa$ B [6]. Clinolipid ${ }^{\circledR}$ has also been demonstrated to be beneficial in improving growth rates and fatty acid profiles in VLBW infants to a greater extent, when compared to soybean-only ILEs [22]. When compared to them, Clinolipid ${ }^{\circledR}$ has been demonstrated to be tolerable and safe [23] [24]. While levels of plasma free fatty acids may not differ between soybean oil and olive oil based ILEs, it has been shown that oleic and linoleic acid levels increase with olive oil based ILEs, while they decrease and increase less significantly with soybean oil-based ILEs, respectively [24]. Reduction in triglyceride levels of approximately $70 \mathrm{mg} / \mathrm{dL}$ has been observed when patients are switched from olive oil based emulsions to those with multiple sources, suggesting that more complex emulsions may be beneficial in avoiding hypertriglyceridemia [25]. Figure 1 gives the timeline of approval for all the different emulsions. Although, the FDA currently has listed its marketing status as discontinued.

\subsection{Smoflipid}

Smoflipid $^{\circledR}$ is the newest mixed-oil emulsion currently for adults. It is not yet approved for pediatrics in the United States but there is plenty of experience around the world in this population to foresee approval, once current studies in children are finalized and presented to the FDA. It combines oils from 4 different sources: $30 \%$ soybean oil, $30 \%$ MCTs, $25 \%$ olive oil and $15 \%$ fish oil. Current data on outcomes concerning specific benefits are still somewhat limited; however, there are several studies supporting its safety and efficacy [26] [27] [28]. A study conducted by Klek et al. demonstrated Smoflipid ${ }^{\circledR}$ to be effective and safe in patients with intestinal failure when administered over a 4 -week period. Furthermore,

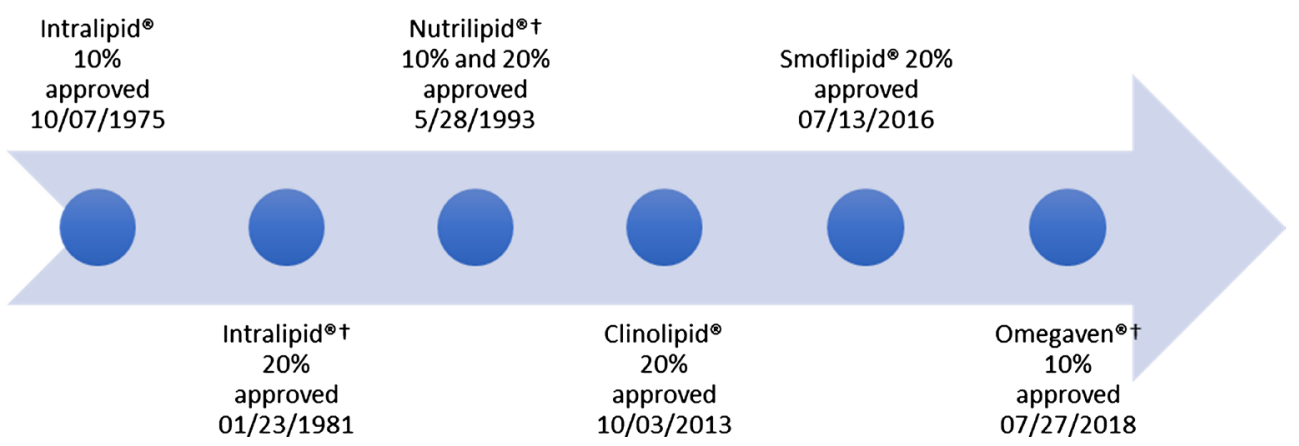

Figure 1. FDA-listed approval dates for ILEs. $\dagger$ indicates ILEs with pediatric approval. 
this study demonstrated that it has the potential to improve fatty acid profiles [26]. EPA and DHA were increased and plasma omega- 3 to omega- 6 fatty acid ratios were reduced approximately $17.35 \%$ from baseline in the experimental group compared to $0.55 \%$ with soybean oil ILEs as a control group. Several studies have indicated an associated increase in $\alpha$-tocopherol concentrations with the use of Smoflipid ${ }^{\circledR}$ [26] [27] [28]. Plasma levels of bilirubin, alanine, and aspartate transaminases have been shown to decrease with the administration of this emulsion, although whether this is a significant decrease is unclear [26] [27] [28]. Several studies suggest there may be hepato-protective properties with this new lipid emulsion that are not present in previous formulations [29]. When compared to soybean oil-based ILEs, Smoflipid ${ }^{\circledR}$ has demonstrated a less significant increase in the activation of liver enzymes and phospholipid-apo A1 protein ratios, indicating better-preserved liver function [30]. Smoflipid ${ }^{\circledR}$, containing $15 \%$ fish-oil, has been sought after to decrease hepatoxicity and improve patient outcomes [24] [25]. Like all ILEs, it is associated with fat overload syndrome [31]. Smoflipid $^{\circledR}$ was demonstrated to produce significantly reduced F2-isoprostane (an oxidative stress marker) levels when compared to Clinolipid ${ }^{\circledR}$ [32]. Preliminary research indicates a little effect on growth and no improvement in mortality in preterm infants given Smoflipid ${ }^{\circledR}$ in comparison to those given Clinolipid ${ }^{\circledR}$ [33]. There are significantly fewer head-to-head trials between these two mixed-oil emulsions as opposed to soybean-based ILEs.

Given the lower content of soybean oil compared to Intralipid $^{\circledR} /$ Nutrilipid $^{\circledR}$, the same questions arise regarding the risk of EFAD. Clinicians are evaluating whether an equivalent dose of the essential fatty acids administered with soybean oil ILEs should be targeted with Smoflipid. Comparable doses can be achieved for linoleic and $\alpha$-linolenic acid, but not for arachidonic acid without surpassing dosing parameters and severely increasing the risk of fat overload [34]. The manufacturer has advised practitioners to provide at least $2 \mathrm{~g} / \mathrm{kg} /$ day of Smoflipid to avoid the risk of EFAD but this should be confirmed with clinical studies on infants and/or children that require long-term PN therapy.

As more and more Smoflipid ${ }^{\circledR}$ is used, it is important to understand practical and logistical differences between this agent and the traditional soybean-based ILEs. Pharmacists can be a great resource to medical teams, given their drug expertise, to provide information regarding co-administration with other medications that patients may receive. Unfortunately, there is a significant paucity of published compatibility data with many medications. Such data is important as some medications are lipophilic in nature and can be trapped in the lipid particles, never reaching the intended site of action; or due to $\mathrm{pH}$ and/or charge imbalance, some medications may affect its stability leading to "cracking" of the emulsion [34]. Pertinent information provided by Fresenius Kabi is summarized in Table 2. These tests were conducted with a PN admixture containing Trophamine ${ }^{\circledR}$ (BBraun Medical Inc., Bethlehem, PA) co-infused with Smoflipid ${ }^{\circledR}$ via a Y-site and each agent listed below co-administered via second Y-site at a single time. 
Table 2. Y-site compatibility of medications with PN admixtures containing Smoflipid.

\begin{tabular}{ccc}
\hline Medication & Concentration & Y-site compatibility \\
\hline Fentanyl & $50 \mathrm{mcg} / \mathrm{mL}$ & Yes \\
Furosemide & $2 \mathrm{mg} / \mathrm{mL}$ & Yes \\
Midazolam & $0.5 \mathrm{mg} / \mathrm{mL}$ & Yes \\
Morphine Sulfate & $1 \mathrm{mg} / \mathrm{mL}$ & Yes \\
Ranitidine & $2.5 \mathrm{mg} / \mathrm{mL}$ & Yes \\
Dopamine & $3.2 \mathrm{mg} / \mathrm{mL}$ & No \\
Famotidine & $2.5 \mathrm{mg} / \mathrm{mL}$ & No \\
\hline
\end{tabular}

Anecdotal experience by pediatric pharmacists has been reported with uneventful administration with dexmedetomidine and insulin, as well as certain concentrations of ceftazidime, dobutamine, fluconazole, metronidazole and vancomycin [35]. A study analyzed compatibility with a continuous infusion of ibuprofen revealing that concentrations up to $1.25 \mathrm{mg} / \mathrm{mL}$ were physically and chemically compatible with Smoflipid ${ }^{\mathbb{B}}$ [36]. It is prudent to assume that if there is any existing incompatibility between a medication and a pure soybean-based ILE, then it would remain incompatible as $30 \%$ of Smoflipid ${ }^{\circledR}$ contains soybean oil. As mentioned in a previous section, soybean-based ILEs have been used in emergency/critical care settings to rescue patients from the toxic effects of certain lipophilic drugs after overdose. Only an animal study has been published showing the reversal of symptoms with Smoflipid ${ }^{\circledR}$ after bupivacaine intoxication [37].

All lipid emulsions reviewed in this article have shown safe outcomes in terms of their incidence of hypertriglyceridemia when following appropriate dosing parameters. No studies have yielded advantages of using one over the other in terms of growth outcomes, which is what they have been approved for as an additive to parenteral nutrition and not a medication treating a condition. There could be theoretical benefits given their composition. Those containing omega-3 fatty acids providing anti-inflammatory qualities or those with MCT oils helping with a more diverse fatty acid intake. So far, studies have not shown definitive evidence for manufacturers to determine such as a property or indication. Providers will have to weigh the risk/benefit ratio on whether they want to incorporate these new ILEs into their operational stock due to clinical scenarios where it might preclude its use due to lack of basic compatibility information and lack of approval for the pediatric population. More research in this area will go a long way in expanding the working knowledge of the medical community in regards to the use of these newer lipid emulsions in the clinical setting besides nutrition support. The U.S. market may not be settled yet in terms of mixed-oil ILEs options. BBraun Medical Inc. is working towards introducing a mixed-oil emulsion similar in composition to their Lipidem ${ }^{\circledR}$ product available in Europe. 


\section{Conclusion}

New ILEs have made their way to pediatrics, albeit with off-label use. While differences in their composition could offer therapeutic benefits for complications and/or deficiencies observed with the traditional ILEs, questions remain on the risk of EFAD and compatibility with other medications. Manufacturer recommendations are pointing to a $2 \mathrm{~g} / \mathrm{kg} /$ day dosing of Smoflipid ${ }^{\circledR}$ to avoid EFAD and safe co-administration with furosemide, dexmedetomidine and narcotic analgesics/sedatives. Other medications may only be compatible at specific concentrations. With the more widespread use of Omegaven ${ }^{\circledR}$, we may find equivalent information soon enough in these same aspects. More clinical studies demonstrating long-term administration of either emulsion need to be published. Such information can guide clinicians on its optimal use to alleviate and/or prevent PNALD, or consider them for other interventions, such as salvage from lipophilic-drug overload.

\section{Conflicts of Interest}

The authors declare no conflicts of interest regarding the publication of this paper.

\section{References}

[1] Mattox, T.W. and Crill, C.M. (2011) Parenteral Nutrition. In: DiPiro, J.T., et al., Eds., Pharmacotherapy. A Pathophysiologic Approach, 8th Edition, McGraw-Hill, New York, 2505-2525.

[2] Ruan, W., French, D., Wong, A., Drasner, K. and Wu, A.H. (2012) A Mixed (Longand Medium-Chain) Triglyceride Lipid Emulsion Extracts Local Anesthetic from Human Serum in Vitro More Effectively than a Long-Chain Emulsion. Anesthesiology, 116, 334-339. https://doi.org/10.1097/ALN.0b013e318242a5f1

[3] Raman, M., Almutairdi, A., Mulesa, L., Alberda, C., Beattie, C. and Gramlich, L. (2017) Parenteral Nutrition and Lipids. Nutrients, 9, E388. https://doi.org/10.3390/nu9040388

[4] Amissi, S., Boisrame-Helms, J., Burban, M., et al. (2017) Lipid Emulsions Containing Medium Chain Triacylglycerols Blunt Bradykinin-Induced Endothelium-Dependent Relaxation in Porcine Coronary Artery Rings. Lipids, 52, 235-243. https://doi.org/10.1007/s11745-016-4225-y

[5] Tampakakis, E., Tabit, C.E., Holbrook, M., et al. (2016) Intravenous Lipid Infusion Induces Endoplasmic Reticulum Stress in Endothelial Cells and Blood Mononuclear Cells of Healthy Adults. Journal of the American Heart Association, 5, e002574. https://doi.org/10.1161/JAHA.115.002574

[6] Harvey, K.A., Xu, Z., Pavlina, T.M., Zaloga, G.P. and Siddiqui, R.A. (2015) Modulation of Endothelial Cell Integrity and Inflammatory Activation by Commercial Lipid Emulsions. Lipids in Health and Disease, 14, 9. https://doi.org/10.1186/s12944-015-0005-6

[7] Postuma, R., Pease, P.W., Watts, R., Taylor, S. and McEvoy, F.A. (1978) Essential Fatty Acid Deficiency in Infants Receiving Parenteral Nutrition. Journal of Pediatric Surgery, 13, 393-398. https://doi.org/10.1016/S0022-3468(78)80463-1

[8] Barr, L.H., Dunn, G.D. and Brennan, M.F. (1981) Essential Fatty Acid Deficiency 
during Total Parenteral Nutrition. Annals of Surgery, 193, 304-311. https://doi.org/10.1097/00000658-198103000-00009

[9] Ibrahim, H.M., Jeroudi, M.A., Baier, R.J., Dhanireddy, R. and Krouskop, R.W. (2004) Aggressive Early Total Parental Nutrition in Low-Birth-Weight Infants. Journal of Perinatology, 24, 482-486. https://doi.org/10.1038/sj.jp.7211114

[10] Koksal, N., Kavurt, A.V., Cetinkaya, M., Ozarda, Y. and Ozkan, H. (2011) Comparison of Lipid Emulsions on Antioxidant Capacity in Preterm Infants Receiving Parenteral Nutrition. Pediatrics International, 53, 562-566. https://doi.org/10.1111/j.1442-200X.2011.03335.x

[11] Siqueira, J., Smiley, D., Newton, C., et al. (2011) Substitution of Standard Soybean Oil with Olive Oil-Based Lipid Emulsion in Parenteral Nutrition: Comparison of Vascular, Metabolic, and Inflammatory Effects. The Journal of Clinical Endocrinology \& Metabolism, 96, 3207-3216. https://doi.org/10.1210/jc.2011-0480

[12] Visschers, R.G., Olde Damink, S.W., Gehlen, J.M., Winkens, B., Soeters, P.B. and van Gemert, W.G. (2011) Treatment of Hypertriglyceridemia in Patients Receiving Parenteral Nutrition. The Journal of Clinical Endocrinology \& Metabolism, 35, 610-615. https://doi.org/10.1177/0148607110389616

[13] Mirtallo, J.M., Dasta, J.F., Kleinschmidt, K.C. and Varon, J. (2010) State of the Art Review: Intravenous Fat Emulsions: Current Applications, Safety Profile, and Clinical Implications. Annals of Pharmacotherapy, 44, 688-700. https://doi.org/10.1345/aph.1M626

[14] Cooke, R.J., Yeh, Y.Y., Gibson, D., Debo, D. and Bell, G.L. (1987) Soybean Oil Emulsion Administration during Parenteral Nutrition in the Preterm Infant: Effect on Essential Fatty Acid, Lipid, and Glucose Metabolism. The Journal of Pediatrics, 111, 767-773. https://doi.org/10.1016/S0022-3476(87)80265-2

[15] Tillman, E.M., Helms, R.A. and Black, D.D. (2012) Eicosapentaenoic Acid and Docosahexaenoic Acid Synergistically Attenuate Bile Acid-Induced Hepatocellular Apoptosis. JPEN Journal of Parenteral and Enteral Nutrition, 36, 36-42. https://doi.org/10.1177/0148607111409588

[16] Tillman, E.M., Crill, C.M., Black, D.D., et al. (2011) Enteral Fish Oil for Treatment of Parenteral Nutrition-Associated Liver Disease in Six Infants with Short-Bowel Syndrome. Pharmacotherapy, 31, 503-509. https://doi.org/10.1592/phco.31.5.503

[17] Lam, H.S., Tam, Y.H., Poon, T.C., et al. (2014) A Double-Blind Randomised Controlled Trial of Fish Oil-Based versus Soy-Based Lipid Preparations in the Treatment of Infants with Parenteral Nutrition-Associated Cholestasis. Neonatology, 105, 290-296. https://doi.org/10.1159/000358267

[18] Puder, M., Valim, C., Meisel, J.A., et al. (2009) Parenteral Fish Oil Improves Outcomes in Patients with Parenteral Nutrition-Associated Liver Injury. Annals of Surgery, 250, 395-402.

[19] Calkins, K.L., Dunn, J.C., Shew, S.B., et al. (2014) Pediatric Intestinal Failure-Associated Liver Disease Is Reversed with 6 Months of Intravenous Fish Oil. JPEN Journal of Parenteral and Enteral Nutrition, 38, 682-692. https://doi.org/10.1177/0148607113495416

[20] Gura, K.M., Lee, S., Valim, C., et al. (2008) Safety and Efficacy of a Fish-Oil-Based Fat Emulsion in the Treatment of Parenteral Nutrition-Associated Liver Disease. Pediatrics, 121, e678-e686. https://doi.org/10.1542/peds.2007-2248

[21] Le, H.D., Meisel, J.A., de Meijer, V.E., Gura, K.M. and Puder, M. (2009) The Essentiality of Arachidonic Acid and Docosahexaenoic Acid. Prostaglandins, Leukotrienes \& Essential Fatty Acids, 81, 165-170. 
https://doi.org/10.1016/j.plefa.2009.05.020

[22] Vlaardingerbroek, H., Vermeulen, M.J., Carnielli, V.P., Vaz, F.M., van den Akker, C.H. and van Goudoever, J.B. (2014) Growth and Fatty Acid Profiles of VLBW Infants Receiving a Multicomponent Lipid Emulsion from Birth. Journal of Pediatric Gastroenterology and Nutrition, 58, 417-427. https://doi.org/10.1097/MPG.0000000000000280

[23] Demirel, G., Oguz, S.S., Celik, I.H., Erdeve, O., Uras, N. and Dilmen, U. (2012) The Metabolic Effects of Two Different Lipid Emulsions Used in Parenterally Fed Premature Infants-A Randomized Comparative Study. Early Human Development, 88, 499-501. https://doi.org/10.1016/j.earlhumdev.2011.12.008

[24] Webb, A.N., Hardy, P., Peterkin, M., et al. (2008) Tolerability and Safety of Olive Oil-Based Lipid Emulsion in Critically Ill Neonates: A Blinded Randomized Trial. Nutrition, 24, 1057-1064. https://doi.org/10.1016/j.nut.2008.05.004

[25] Mateu-de Antonio, J. and Florit-Sureda, M. (2016) New Strategy to Reduce Hypertriglyceridemia during Parenteral Nutrition While Maintaining Energy Intake. JPEN Journal of Parenteral and Enteral Nutrition, 40, 705-712. https://doi.org/10.1177/0148607114549253

[26] Klek, S., Chambrier, C., Singer, P., et al. (2013) Four-Week Parenteral Nutrition Using a Third Generation Lipid Emulsion (SMOFlipid) - A Double-Blind, Randomised, Multicentre Study in Adults. Clinical Nutrition, 32, 224-231.

https://doi.org/10.1016/j.clnu.2012.06.011

[27] Grimm, H., Mertes, N., Goeters, C., et al. (2006) Improved Fatty Acid and Leukotriene Pattern with a Novel Lipid Emulsion in Surgical Patients. European Journal of Nutrition, 45, 55-60. https://doi.org/10.1007/s00394-005-0573-8

[28] Goulet, O., Antebi, H., Wolf, C., et al. (2010) A New Intravenous Fat Emulsion Containing Soybean Oil, Medium-Chain Triglycerides, Olive Oil, and Fish Oil: A Single-Center, Double-Blind Randomized Study on Efficacy and Safety in Pediatric Patients Receiving Home Parenteral Nutrition. JPEN Journal of Parenteral and Enteral Nutrition, 34, 485-495. https://doi.org/10.1177/0148607110363614

[29] Muhammed, R., Bremner, R., Protheroe, S., Johnson, T., Holden, C. and Murphy, M.S. (2012) Resolution of Parenteral Nutrition-Associated Jaundice on Changing from a Soybean Oil Emulsion to a Complex Mixed-Lipid Emulsion. Journal of Pediatric Gastroenterology and Nutrition, 54, 797-802. https://doi.org/10.1097/MPG.0b013e3182447daf

[30] Antebi, H., Mansoor, O., Ferrier, C., et al. (2004) Liver Function and Plasma Antioxidant Status in Intensive Care Unit Patients Requiring Total Parenteral Nutrition: Comparison of 2 Fat Emulsions. JPEN Journal of Parenteral and Enteral Nutrition, 28, 142-148. https://doi.org/10.1177/0148607104028003142

[31] Hojsak, I. and Kolacek, S. (2014) Fat Overload Syndrome after the Rapid Infusion of SMOFlipid Emulsion. JPEN Journal of Parenteral and Enteral Nutrition, 38, 119-121. https://doi.org/10.1177/0148607113482001

[32] Deshpande, G., Simmer, K., Deshmukh, M., Mori, T.A., Croft, K.D. and Kristensen, J. (2014) Fish Oil (SMOFlipid) and Olive Oil Lipid (Clinoleic) in Very Preterm Neonates. Journal of Pediatric Gastroenterology and Nutrition, 58, 177-182. https://doi.org/10.1097/MPG.0000000000000174

[33] Najm, S., Lofqvist, C., Hellgren, G., et al. (2017) Effects of a Lipid Emulsion Containing Fish Oil on Polyunsaturated Fatty Acid Profiles, Growth and Morbidities in Extremely Premature Infants: A Randomized Controlled Trial. Clinical Nutrition ESPEN, 20, 17-23. https://doi.org/10.1016/j.clnesp.2017.04.004 
[34] Washington, C., Athersuch, A. and Kynoch, D.J. (1990) The Electronic Kinetic Properties of Phospholipid-Stabilized Fat Emulsions. IV. The Effect of Glucose and pH. International Journal of Pharmaceutics, 64, 217-222. https://doi.org/10.1016/0378-5173(90)90271-5

[35] Cober, M.P., Gura, K.M. and Plogsted, S. (2018) Challenges in Pediatric Nutrition: What's up with Lipid Emulsions? New Products, Dosing Strategies and Potential for Fatty Acid Deficiency. 27th PPAG Annual Meeting \& 2018 Pediatric Pharmacy Conference, Salt Lake City, 26 April 2018.

[36] Garcia, J., Garg, A., Song, Y., Fotios, A., Andersen, C. and Garg, S. (2018) Compatibility of Intravenous Ibuprofen with Lipids and Parenteral Nutrition, for Use as a Continuous Infusion. PLOS ONE, 13, e0190577.

https://doi.org/10.1371/journal.pone.0190577

[37] Melo Mde, S., Bonfim, M.R., Dreyer, E., Bassanezi, B.S. and Udelsmann, A. (2012) Hemodynamic Changes in Lipid Emulsion Therapy (SMOFlipid) for Bupivacaine Toxicity in Swines. Acta Cirurgica Brasileira, 27, 318-324.

https://doi.org/10.1590/S0102-86502012000400007 